\title{
Investing: NFTs? How about choosing science?
}

\author{
Tam-Tri Le \\ Centre for Interdisciplinary Social Research \\ Phenikaa University, Hanoi, Vietnam
}

2022 February 25

Note: this short paper contains sarcasm.

Non-fungible token (NFT) is one of the top buzzwords of 2021 and continues to be the focus of attention in early 2022, for various reasons - good and bad.

While NFT is built based on blockchain technology, their application so far is dominantly driven by financial schemes unrelated to the technology. Arguably, the famous memes of "selling JPEG" point at the reality that many NFT projects focus on the psychological aspect of traders (e.g. "get rich quick" or "cool club") instead of the intrinsic values provided by blockchain technology. In fact, NFT-related fraudulent incidents usually do not involve advanced technical security problems, but rather more familiar concepts such as Ponzi scheme, Pump-and-Dump, plagiarism, rug-pull, etc. In brief, there are many opportunities for illegal and/or immoral exploitation (Chow, 2022).

The situation surrounding NFT is debatable. However, the truth is that it has been pulling in a huge amount of money, as NFT sales hit \$25 billion in 2021 (Howcroft, 2022).

It makes me wonder: there is something, a fundamental activity of humanity, that gives enormous payoff, enough to turn wooden shacks into metropolises: science; but sometimes the public may consider the investment to be too much for its worth (Vuong, 2018).

You are free to speculate as much as you want regarding science's insane potentials: flying, global communication, curing diseases, creating virtual worlds, even enabling NFTs! Oh wait, all of those have already been achieved. I guess the return is pretty solid.

Perhaps, science is also a good target of investment for celebrities and the upper class. Imagine how cool it is to be the funder of the project leading to curing cancer instead of some receipts of JPEGs?

\section{References}

Chow, A. (2022). "The Problem With NFTs": A Crypto Expert Responds to a Viral Takedown.

Time. https://time.com/6144332/the-problem-with-nfts-video/ 
Howcroft, E. (2022, January 11). NFT sales hit $\$ 25$ billion in 2021, but growth shows signs of slowing. Reuters. https://www.reuters.com/markets/europe/nft-sales-hit-25-billion-2021growth-shows-signs-slowing-2022-01-10/

Vuong, Q.-H. (2018). The (ir)rational consideration of the cost of science in transition economies. Nature Human Behaviour, 2(1), 5. 